\title{
Intenção de comportamento socialmente responsável do consumidor: sua relação com os valores humanos básicos
}

\author{
Fabiana Queiroga ${ }^{1}$ \\ Valdiney V. Gouveia \\ Maria da Penha L. Coutinho \\ Viviany Pessoa \\ Maja Meira
}

\begin{abstract}
Resumo
Este estudo teve como objetivo explorar a relação entre a intenção de comportamento do consumidor e os valores humanos, abordando temas como proteção ao meio ambiente e a outras pessoas. Participaram do estudo universitários com idade média de 21 anos $(\mathrm{DP}=4,6)$ e a maioria foi do sexo feminino (72,4\%). Os estudantes responderam coletivamente em sala de aula a um questionário com questões objetivas sobre comportamento social. Os resultados apontaram para a importância dos valores humanos na compreensão dos processos subjacentes à intenção de compra dos consumidores tendo em vista os aspectos sociais mensurados. A categoria de valores centrais explicou $3 \%$ da variância para preocupação ambiental; 4\% para preocupação com a reciclagem; e para preocupação social a variância explicada foi de $5 \%$. Tais resultados indicaram que a tipologia dos valores humanos apresentou coerência na explicação do construto estudado e que existe relação compreensível entre ambos.

Palavras-chave: Intenção de compra; Valores humanos; Comportamento responsável.
\end{abstract}

\section{Intention of social responsible conduct consumer: relationship with human basic values}

\begin{abstract}
This study had the objective of exploring the relationship between the intention of consumer behavior and human values approaching subjects as environmental protection and the protection of other people. They had participated of the study university with average age of 21 years (s.d. $=4.6)$ and a majority was females $(72.4 \%)$. The students had collectively answered in classroom a questionnaire with objective questions on social behavior. The results had pointed with respect to importance of the human values in the understanding of the underlying processes to the intention of purchase of the consumers considering the social aspects measured. The category of central values explained $3 \%$ of the variance for environmental concern; $4 \%$ for concern with recycling; and for social concern the explained variance was of $5 \%$. Such results had indicated that the typology of human values presented coherence in the explanation of the studied construct and that an understandable relationship between them exists.

Keywords: Intention of purchase; Human values; Responsible conduct.
\end{abstract}

\section{Introdução}

Nos últimos anos, os estudos interessados nos fatores associados à escolha do consumidor por determinado produto têm conseguido avanços importantes tanto na quantidade quanto na qualidade das pesquisas realizadas sobre comportamento do consumidor. Nas primeiras publicações sobre o tema, podia ser observada uma tendência de se compreender o comportamento de compra fundamentada em um único modelo ou numa "grande teoria" (Allen, 2000). Contudo, durante os anos 1980, a ênfase nesse tipo de compreensão começa a perder sua força e aparecem visões advogando que o comportamento do consumidor é complexo demais para ser capturado em um modelo único e também não é capaz de englobar a gama de processos psicológicos envolvidos nesse comportamento.

Apesar de outros campos como Economia e Antropologia também exercerem significativa influência nas pesquisas sobre este tema, será enfatizada no presente estudo a abordagem de base psicológica atributo-mediação e a abordagem do significado do produto, por levarem em conta a discussão da influência de outro construto de interesse nesta pesquisa - os valores bumanos.

A abordagem atributo-mediação (ver estudos como os de Gutman, 1982) sugere que os valores influenciam a preferência por determinado produto de forma indireta, por meio da importância observada para os atributos daquele produto que, por sua vez, guiam a avaliação do consumidor sobre o produto e a sua

\footnotetext{
${ }^{1}$ Endereço para correspondência:

Condomínio Master Place, Asa Norte - Bloco F - Un. 19 - 70790-120 - Brasília-DF

Fax: (61) 3448-0364

E-mail: fabiana@cespe.unb.br
} 
compra. A proposta desta abordagem é especificar tanto a intervenção de variáveis entre os valores humanos e o comportamento quanto a maneira com que estas variáveis são utilizadas pelos consumidores nos seus julgamentos sobre produtos.

Essa postura contrasta com os estudos que argumentam a influência direta dos valores (como em Henry, 1976) ou aqueles em que a mediação ocorre por meio da atitude (assumida como um construto diferente de valor em Homer \& Kahle, 1988, por exemplo). De maneira geral, os autores que enfatizam a mediação dos valores estão apontando para a importância de especificar a estrutura cognitiva que os valores exercem na preferência por produtos.

Todavia, Allen (2000) ressalta duas críticas básicas que podem ser observadas na abordagem atributo-mediação. A primeira delas é de que essa abordagem não contempla a compreensão da influência dos valores na avaliação dos consumidores para atributos de produtos não-palpáveis, tais como imagem, simbolismo e estética. A outra crítica é que esta abordagem está baseada nas teorias de Fishbein (1967) e Rosemberg (1956), que assumem que os consumidores avaliam produtos atributo por atributo e que o julgamento de cada atributo do produto independentemente contribui para avaliar o mesmo de forma global. Essa suposição pode ser verdadeira para atributos de produtos palpáveis, mas não para atributos de produtos não-palpáveis mencionados anteriormente (imagem, simbolismo e estética), nos quais as avaliações são inevitavelmente feitas com o olhar no todo, e não apenas nas partes.

Procurando preencher essas lacunas, a abordagem do significado do produto proposta por Allen (1997) e Allen e Ng (1999) sugere inicialmente que a própria compreensão da influência dos valores pode ser ampliada a partir da quebra do sistema geral hierárquico valor-atitude-comportamento. Dessa forma, o foco desta abordagem está no significado dos produtos para os consumidores, em como os objetos são julgados e as funções psicológicas representadas pelos significados dos produtos. Nas pesquisas que enfocam essa abordagem, pode estar presente uma classificação de quatro tipos de significados: utilidade, divertimento, representação das ligações interpessoais e identidade e autoexpressão (conforme proposta de Richins, 1994) ou simplesmente a distinção de duas categorias: utilidade (instrumental) e simbólica.

Assim, de acordo com a abordagem do significado do produto, é a categorização do mesmo feita pelo consumidor que irá determinar o tipo de relação que os valores estabelecerão na escolha do produto. Os valores humanos geralmente terão uma influência indireta na preferência por produtos - pela importância de atributos palpáveis - quando consumidores os avaliam com significado de utilidade. Nesse caso, é feito um tipo de julgamento parcial e o produto assume função instrumental (Allen, 2000). Por outro lado, quando o resultado da avaliação do consumidor é um produto com significado simbólico, é feito um julgamento intuitivo e afetivo, o produto assumindo função expressiva e os valores humanos exercendo influência direta na preferência por ele.

Tendo em vista o número de pesquisas citadas por Allen (2000) realizadas para confirmar a estabilidade deste modelo, o presente estudo pretende verificar em que medida o conjunto de valores presentes na tipologia dos valores humanos básicos proposta por Gouveia (2003) está relacionado com a intenção de comportamento socialmente responsável do consumidor. Para tanto, faz-se necessário destacar algumas considerações sobre os valores humanos e, em especial, sobre a tipologia utilizada nesta pesquisa.

\section{Os valores humanos: principais enfoques teóricos}

Milton Rokeach talvez figure como o teórico mais conhecido a escrever sobre os valores humanos. Em sua obra clássica The nature of human value (1973), o autor comenta que os valores não representam simplesmente palavras ensinadas às crianças; compreendem importantes explicadores de atitudes, sentimentos, comportamentos etc., estando também relacionados com atributos econômicos, sociais e culturais. Para a mensuração, ele apresenta um conjunto de 36 valores divididos igualmente entre instrumentais (por exemplo, salvação, um mundo em paz) e terminais (por exemplo, inteligente, responsável), sendo estes operacionalizados em razão de uma escala de ordem, produzindo medidas ipsativas. Segundo seu modelo, um valor poderia ser definido como

\section{uma crença duradoura de que um modo específico de comportamento ou estado último de existência é pessoal ou socialmente preferivel a um modo de comportamento ou estado final de existência oposto on inverso.} (Rokeach, 1973, p. 5)

Apesar das significativas contribuições de Rokeach (1973), algumas limitações sobre seus estudos são apontadas. Antes de tudo, esse autor distingue o conceito de valor do de atitudes e normas sociais, porém não o faz com o de crença, uma vez que, na sua definição, este é um elemento de extrema importância, dificultando uma maior delimitação do tema. Outro ponto a ser questionado diz respeito à sua metodologia de escolha dos valores que, como o próprio autor

Psico-USF, v. 11, n. 2, p. 239-248, jul./ dez. 2006 
admite, é intuitiva, não permitindo que diferentes pesquisadores possam identificá-la sem ambigüidades. A divisão entre valores instrumentais e terminais não se confirma em resultados de pesquisas posteriores.

Sendo assim, outros modelos vêm sendo propostos, como o de Shalom H. Schwartz, que concebe os valores como desejáveis, com objetivos transituacionais, variando em importância e servindo como princípios-guia na vida das pessoas (Schwartz, 1992). Recuperando as idéias iniciais de Rokeach (1973), Schwartz (1994) propõe uma teoria sobre o conteúdo e a estrutura dos tipos motivacionais de valores, que supõe serem universais. Não apresenta nenhuma teoria específica sobre a origem dos valores humanos, sendo a maioria dos que compõem sua escala retirados do Rokeach Value Survey. Sua idéia básica é de que existem alguns elementos, itens ou valores específicos que se reúnem em razão do tipo motivacional que cumprem, dando origem ao que chama de tipos motivacionais de valores.

Estudos empíricos realizados em mais de 40 culturas sugerem a presença de 10 tipos motivacionais, com alguns dos valores descritivos entre parênteses: autodireção (independente, curioso), estimulação (uma vida excitante, atrevido), hedonismo (prazer, desfrutar da vida), êxito (ambicioso, capaz), poder (poder social, autoridade), benevolência (amável, honesto), conformidade (educado, obediente), tradição (devoto, respeito pela tradição), segurança (segurança familiar, ordem social) e universalismo (aberto, um mundo de beleza). Apesar da medida desse autor já ter sido traduzida para mais de 20 línguas e ser utilizada em mais de 40 países em pesquisas interculturais, algumas críticas também foram formuladas em relação ao seu modelo, principalmente por ter sido construído sem um embasamento teórico adequado ou uma concepção coerente sobre a natureza humana (Gouveia, 2003; Molpeceres, 1994).

Diferentemente dos autores até agora referenciados, Inglehart (1991), outro teórico com bastante destaque nesse âmbito do conhecimento, propõe uma teoria sobre os valores humanos fundamentada na idéia de escassez e socialização. A partir da Teoria da Hierarquia das Necessidades (Maslow, 1954/1970), Inglehart define duas dimensões por meio das quais pretende identificar as mudanças geracionais e comparar as culturas nacionais: materialismo (diz respeito à satisfação de necessidades mais básicas e de segurança, isto é, valores materiais) e pós-materialismo (origina-se da satisfação materialista, desencadeando os valores espirituais).

Psico-USF, v. 11, n. 2, p. 239-248, jul./ dez. 2006
Segundo Inglehart (1991), naquelas sociedades em que não estão satisfeitas as necessidades de segurança (física ou econômica), o materialismo seria o padrão valorativo predominante. Contrariamente, nas sociedades mais ricas, as quais ele chama de sociedades industriais avançadas, seria imperativa a dimensão valorativa denominada de pós-materialismo. Essas conjecturas, que são em princípio simples, não necessariamente correspondem à realidade. É possível que em países ricos ou com pessoas que na atualidade gozem de estabilidade econômica, siga-se dando importância à orientação materialista.

A explicação para tanto parece evidente: o processo de socialização pelo qual passaram as pessoas. É, portanto, necessário atentar para o período e o contexto em que elas foram socializadas, correspondendo aos anos de infância e adolescência. Alguém que viveu em um contexto de escassez, por exemplo, durante uma guerra, pode seguir dando importância à segurança física e econômica, ainda que tenha garantido a satisfação dessas necessidades.

Diante dos modelos existentes e reconhecendo a necessidade de diferenciar os valores de outros construtos com os quais costumam ser confundidos, Gouveia (2003) pensou na possibilidade de elaborar uma tipologia alternativa. Talvez seu aspecto mais inovador seja assumir a natureza humana como benévola e identificar uma teoria específica da qual deriva sua lista de valores. Esse modelo servirá, neste estudo, de base teórica para compreender os valores, exigindo assim que se faça um maior aprofundamento.

Gouveia (2003) apresenta sua tipologia dos valores humanos básicos, conceituando-os como

categorias de orientação que são desejáveis, baseadas nas necessidades humanas e nas pré-condições para satisfazê-las, sendo adotadas por atores sociais. Tais valores apresentam diferentes magnitudes e seus elementos constitutivos podem variar a partir do contexto social ou cultural em que a pessoa está inserida. (p. 293)

Assim como Inglehart (1991), para identificar cada valor básico, Gouveia tomou como referência a Teoria das Necessidades de Maslow (1954/1970), cujos principais fundamentos são: (1) as necessidades humanas são relativamente universais; (2) são neutras ou positivas; (3) obedecem a uma hierarquia; (4) o homem caminha em direção à auto-realização; e (5) a pessoa é um todo integrado e organizado. Em razão da Teoria das Necessidades, foram identificados 24 valores básicos agrupados conforme apresenta a Figura 1. 
PESSOAIS

\begin{tabular}{|c|c|}
\hline Experimentação & Realização \\
Emoção & Exito \\
Sexual & Poder \\
Estimulação & Prestígio \\
Prazer & Privacidade \\
& Autodireção \\
\hline
\end{tabular}

\section{MODAIS}

\begin{tabular}{|c|c|}
\hline Existência & Suprapessoal \\
Sobrevivência & Maturidade \\
Estabilidade & Justiça Social \\
Pessoal & Beleza \\
Saúde & Sabedoria \\
\hline
\end{tabular}

\section{SOCIAIS}

\begin{tabular}{|c|}
\hline Normativo \\
Tradição \\
Ordem Social \\
Religiosidade \\
Obediência
\end{tabular}

Figura 1 - Tipologia dos valores humanos básicos.

Teoricamente, esses valores humanos básicos conformam um sistema valorativo fundamentado em três critérios de orientação, descritos a seguir.

Valores pessoais. Dá-se prioridade aos próprios benefícios ou às condições nas quais possam ser obtidos sem um marco de referência particular. $\mathrm{Na}$ tipologia de Rokeach (1973), compreendem os valores de foco intrapessoal, centrados na própria pessoa. Dividem-se em: (a) valores de experimentação: descobrir e apreciar novos estímulos, enfrentar situações-limite, assim como buscar satisfação sexual (estimulação, emoção, prazer e sexual); e (b) valores de realização: além de experimentar novos estímulos, a realização, o sentimento de ser importante e poderoso, ser uma pessoa com identidade e espaço próprio é algo que também deve orientar seu comportamento. Quem assume esse padrão de valores costuma manter relações pessoais contratuais, com o fim de obter benefícios (êxito, poder, prestígio, autodireção e privacidade).

Valores centrais. Esta etiqueta é utilizada aqui para indicar o caráter central ou neutro desses valores; eles figuram entre os valores pessoais e sociais e são compatíveis com eles. Em relação à tipologia de Schwartz (1994), tais valores serviriam a interesses mistos (individualistas e coletivistas). Os valores centrais podem ser divididos em dois conjuntos de valores, considerando suas funções psicossociais: (a) valores de existência: expressam uma preocupação por garantir a sua própria existência orgânica (estabilidade pessoal, saúde e sobrevivência). A ênfase não é sobre a individualidade, mas sobre a existência individual. Nesse sentido, tais valores não são incompatíveis com aqueles denominados de pessoais ou sociais. Eles são importantes para todas as pessoas, principalmente em contextos de escassez; e (b) valores suprapessoais: as pessoas que assumem esses valores buscam cumprir seus objetivos independentemente do grupo ou da condição social. Descrevem alguém que é maduro, tem menos preocupações materiais, que é menos limitado a características descritivas ou traços específicos para iniciar uma relação ou promover benefícios (belez̧a, conbecimento, justiça social e maturidade). Tais valores enfatizam a importância de todas as pessoas, não exclusivamente dos indivíduos que compõem o grupo de pertença. Desse modo, são perfeitamente compatíveis com os valores pessoais e sociais. Embora Rokeach (1973) utilize a expressão "valores supraindividuais", ele não expressa a mesma idéia aqui tratada. Espera-se que os tipos motivacionais segurança e universalismo (Schwartz, 1994) correlacionem-se com os valores de existência e suprapessoais, respectivamente.

Valores sociais. Quem assume esse padrão valorativo orienta-se em direção aos demais. Seu comportamento pode traduzir o desejo de sentir-se considerado, assegurar aceitação e integração no seu grupo, ou manter um nível indispensável de harmonia entre os diversos atores sociais de um contexto específico. Essa orientação de valores divide-se em duas categorias: (a) normativos: ênfase na vida social, na busca de estabilidade do grupo, nos comportamentos socialmente corretos e no respeito pelos símbolos e pelos padrões culturais que prevaleceram durante anos; estima-se a ordem acima de qualquer outra coisa (religiosidade, ordem social, tradição e obediência); e (b) interacionais: o sentido comum é o foco de atenção, que neste caso são as demais pessoas. Sua especificidade como conjunto fundamenta-se no interesse por sentirse querido, ter uma amizade verdadeira e uma vida social. São valores relacionais com marcos de referência certamente específicos, como pode ser um amigo, um namorado ou um grupo concreto de vizinhos (afetividade, apoio social, convivencia e honestidade).

Nesse sentido, considerando o papel dos valores humanos na escolha do consumidor por produtos que assumem significado simbólico, conforme 
destacado por Allen (2000), este estudo pretende considerar a preocupação com aspectos sociais na intenção de compra, e verificar em que medida os valores humanos básicos da tipologia de Gouveia (2003) podem explicar esse construto. Para mensuração de intenção de compra será utilizada a Escala de Comportamentos Socialmente Responsáveis do Consumidor (ECSRC) validada para o contexto brasileiro por Queiroga, Gouveia, Coutinho, Vasconcelos e Jesus (2005).

\section{Método}

\section{Delineamento}

O presente estudo é do tipo correlacional. Os valores humanos básicos foram inseridos como variáveis antecedentes (VA) e as pontuações da ECSRC como variáveis conseqüentes (VC).

\section{Amostra}

Participaram deste estudo 298 estudantes da Universidade Federal da Paraíba, distribuídos eqüitativamente nas áreas de Humanas e Saúde (aproximadamente 50\% para ambas). A média de idade dos participantes foi de 21 anos (DP $=4,6$ ) sendo $72,4 \%$ do sexo feminino e o restante $(27,6 \%)$ do sexo masculino. $\mathrm{Na}$ Tabela 1, são apresentados alguns detalhes da caracterização sociodemográfica da amostra. Essa amostra é do tipo não-probabilística, sendo obtida acidentalmente, seguindo a conveniência de contar com voluntários dispostos a responder aos instrumentos.

Tabela 1 - Caracterização sociodemográfica da amostra $(\mathrm{N}=298)$

\begin{tabular}{lccc}
\hline & Freqüência & $\begin{array}{c}\text { Porcent. } \\
(\%)\end{array}$ & $\begin{array}{c}\text { Porcent. } \\
\text { válida (\%) }\end{array}$ \\
\hline $\begin{array}{l}\text { Sexo } \\
\text { Feminino }\end{array}$ & 215 & 72,1 & 27,6 \\
Masculino & 82 & 27,5 & 72,4 \\
\hline Idade & & & \\
17-19 & 150 & 50,4 & 50,4 \\
20-25 & 120 & 40,2 & 40,2 \\
A partir de 25 & 28 & 9,4 & 9,4 \\
\hline Área do Curso & & & \\
Saúde & 146 & 49,9 & 49,0 \\
Humanas & 149 & 50,0 & 51,0 \\
\hline
\end{tabular}

\section{Instrumentos}

Os participantes responderam a um questionário composto pelos seguintes instrumentos. I - Questionário dos Valores Básicos. Este instrumento, elaborado e validado por Gouveia (2003), está composto por 24 itens ou valores específicos, respondidos em uma escala com nove pontos. Inicialmente pede-se ao respondente que leia atentamente e indique em uma escala de 7 pontos, com os extremos $1=$ nada importante e $7=$ muito importante, o grau de importância de cada um dos valores. Uma vez respondido, o participante terá que indicar aquele que considera o mais importante de todos e a seguir deverá indicar o menos importante de todos. Para esses dois valores serão atribuídos os escores 8 e 0 , respectivamente. Estes 24 valores são agrupados em três critérios de orientação: pessoais, centrais e sociais, conforme a teoria antes descrita. Os indicadores de bondade de ajuste para o espaço bi-dimensional obtidos na testagem do modelo teórico foram: $R S Q=$ 0,82 e $S$-Stress $=0,19$. A análise fatorial confirmatória que testou o agrupamento dos valores nas seis funções psicossociais revelou que todos os lambdas $(\chi$, cargas fatoriais) foram diferentes de zero $(t>1,96 ; p<0,05)$, resultando nos seguintes índices de bondade de ajuste: $\chi^{2}$ g.l. $=2,67, G F I=0,91, A G F I=0,89, R M S A=$ 0,05 e $N$ crítico $=279,04$. Em média as funções psicossociais apresentam índice de consistência interna ( $\alpha$ de Cronbach) de 0,51.

II - Escala de Comportamento Socialmente Responsável do Consumidor. Validada para o contexto brasileiro por Queiroga e colaboradores (2005), esse instrumento contém 15 sentenças que visam avaliar com que freqüência o sujeito se comporta de maneira socialmente consciente no momento de comprar seus produtos. Os itens são respondidos em uma escala de freqüência contendo cinco pontos, cujos extremos correspondem a $1=$ nunca e $5=$ sempre. A análise fatorial dos eixos principais (PAF) indicou a presença de 3 fatores que explicam juntos 49,43\% da variância. O fator I, denominado preocupação ambiental, é composto por 5 itens $(\alpha=0,86)$ que expressam um cuidado do consumidor com o meio ambiente ao comprar seus produtos. O fator II, composto por 4 itens $(\alpha=0,75)$, também expressa a preocupação do consumidor com o meio ambiente, mas com o foco na reciclagem dos produtos. Por isso, este fator foi denominado de preocupação com reciclagem. Por fim, o fator III desta escala, denominado preocupação social, apresentou $\alpha=0,70$ e diz respeito à preocupação do consumidor com questões relacionadas ao bem-estar social das pessoas envolvidas tanto na confecção do produto quanto na divulgação deste.

III - Características sociodemográficas. Uma folha contendo questões de caráter sociodemográfico (como idade, sexo, estado civil e grau de instrução) foi apresentada 
ao fim do questionário geral, procurando coletar informações como idade, sexo e estado civil.

\section{Procedimento}

Junto aos responsáveis pelas salas de aula da universidade, os objetivos do estudo foram apresentados com garantia do anonimato e do sigilo das respostas dos participantes. Agrupados nas salas de aula, os alunos regularmente matriculados em um dos cursos oferecidos eram convidados a responder aos questionários, explicitando-se que a participação deveria ser voluntária e que as respostas seriam tratadas de forma coletiva. Contudo, foi esclarecido que elas deveriam ser dadas individualmente.

Os instrumentos foram contrabalançados, procurando evitar o efeito de exposição da informação. Durante a coleta de dados, as intervenções feitas foram unicamente para prestar esclarecimentos de forma e nunca de conteúdo, com a finalidade de evitar diferentes conotações ou significados que pudessem comprometer a resposta do sujeito.

\section{Resultados}

\section{Análises dos pressupostos}

Por meio da distribuição e dos escores padronizados das variáveis foi realizada a identificação dos outliers univariados. Embora se tenha encontrado casos extremos em algumas variáveis (a maioria referente aos valores humanos), nenhum dos casos foi retirado tendo em vista a peculiaridade do construto. Conforme a discussão encontrada na literatura sobre este tema, existe uma tendência de que sujeitos pontuem nos extremos positivos da escala de respostas explicada pelo caráter de desejabilidade intrínseco à própria definição dos valores (Gouveia, 2003).

Em relação ao tamanho da amostra, foi adotado o cálculo recomendado por Tabachnick e Fidell (2001) para que fosse possível prosseguir com as análises de regressão linear múltipla padrão, que seria de 8 vezes o número de variáveis independentes acrescido de 50 casos, visto que cada fator da ECSRC será tomado como variável dependente em modelos separados, tendo como variáveis independentes ora as 6 funções psicossociais, ora os 3 critérios de orientação valorativa. Efetuando-se os cálculos para a situação de maior possibilidade de VI's (caso em que serão consideradas as 6 funções psicossociais e no qual seria exigido um mínimo de 98 sujeitos) é possível observar que o tamanho da amostra $(\mathrm{N}=298)$ viabiliza a realização das análises de regressão planejadas para este estudo. Em relação aos dados faltosos, em decorrência da baixa porcentagem desses casos na amostra (máximo de $2 \%$, no item 12 da ECSRC), optou-se por substituí-los utilizando o método de substituição pela média.

Por meio dos histogramas das variáveis, bem como das medidas de curtose e assimetria, observou-se que nenhuma variável apresenta problemas sérios a esse respeito, não sendo adotada então qualquer transformação. Sobre a linearidade, como se trata de 42 variáveis no total, seria extremamente custoso pedir o scatterplot para todos os pares possíveis de variáveis. Assim, ele foi solicitado apenas entre os fatores que apresentavam as piores distribuições, como: fator III da ECSRC e a função psicossocial dos valores interacionais. E como pode ser visto na Figura 2, embora não se tenha linearidade, de fato, também não há curvilinearidade.

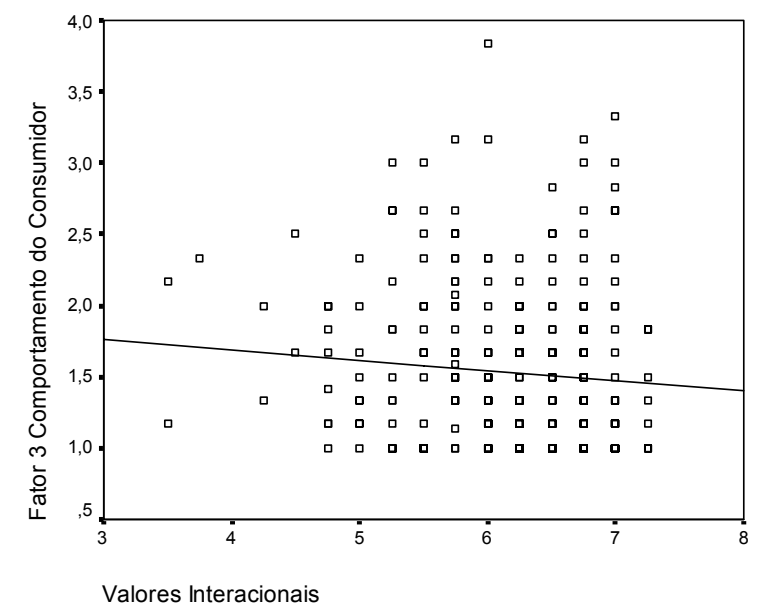

Figura 2 - Scatterplot dos fatores 3 do comportamento do consumidor e a função psicossocial dos valores interacionais

Valores humanos básicos e a relação com a intenção de comportamento socialmente responsável do consumidor

Foi realizada uma regressão linear múltipla com método enter, em que se tomou, separadamente, o grupo das funções psicossociais e o grupo dos critérios de orientação valorativos como variáveis antecedentes e os escores dos fatores da ECSRC como variável critério. O resultado encontrado para a regressão, considerando as funções psicossociais, mostrou que esse conjunto de valores apresenta uma correlação significativa com o fator de preocupação ambiental da ECSRC $(\mathrm{R}=0,29, \mathrm{~F}=$ 4,38; $p<0,000$ ) explicando $8 \%$ da variância neste fator. Por outro lado, considerando-se como preditores o modelo que engloba os critérios de orientação valorativa, a quantidade de variância explicada neste fator foi mais reduzida $(3 \%)$. 
Fazendo uma análise mais detalhada da contribuição de cada variável dos dois modelos, podese observar que, entre as contribuições significativas $(\not p$ $<0,05)$, a função dos valores suprapessoais é que mais produz impacto no fator de preocupação ambiental $(\beta=$
0,42), seguido do critério de orientação dos valores centrais $(\beta=0,37)$. Os valores observados para as inclinações das demais variáveis não indicam contribuições significativas para este fator.

Tabela 2 - Coeficientes observados para a regressão considerando os modelos com as funções psicossociais e os critérios de orientação para o fator de preocupação ambiental

\begin{tabular}{|c|c|c|c|c|c|}
\hline Preditores & $\beta$ & $\begin{array}{l}\text { Erro padrão } \\
\text { de } \beta\end{array}$ & $\begin{array}{c}\beta \\
\text { Padronizado }\end{array}$ & $\mathrm{t}$ & $p$ \\
\hline Constante $^{1}$ & 1,65 & 0,81 & - & 2,03 & 0,043 \\
\hline Constante $^{2}$ & 1,69 & 0,82 & - & 2,06 & 0,040 \\
\hline Pessoais & $-0,17$ & 0,09 & -011 & $-1,87$ & 0,062 \\
\hline Experimentação & 0,00 & 0,07 & 0,00 & 0,01 & 0,993 \\
\hline Realização & $-0,12$ & 0,08 & $-0,10$ & $-1,60$ & 0,112 \\
\hline Modais & 0,37 & 0,11 & 0,19 & 3,11 & 0000 \\
\hline Suprapessoais & 0,42 & 0,09 & 0,29 & 4,83 & 0,002 \\
\hline Existência & 0,00 & 0,09 & $-0,05$ & $-0,81$ & 0,418 \\
\hline Sociais & 0,00 & 0,09 & -004 & $-0,67$ & 0,503 \\
\hline Normativos & 0,00 & 0,07 & 0,07 & 1,04 & 0,298 \\
\hline \multirow[t]{2}{*}{ Interacionais } & $-0,11$ & 0,09 & $-0,07$ & $-1,21$ & 0,228 \\
\hline & $\mathrm{R}$ & $\mathrm{R}^{2}$ & $\mathrm{R}^{2}$ Ajustado & $\begin{array}{l}\text { Erro padrão } \\
\text { da estimativa }\end{array}$ & \\
\hline Funções psicossoais & 0,29 & 0,08 & 0,06 & 1,01 & \\
\hline Critérios de orientação & 0,19 & 0,03 & 0,02 & 1,02 & \\
\hline
\end{tabular}

1. Valor observado para esta componente considerando as funções psicossociais.

2. Valor observado para esta componente considerando os critérios de orientação valorativa.

Os índices de correlação que os valores centrais e suprapessoais estabelecem com o fator de preocupação ambiental indicam que as pessoas que mais pontuam em valores como sobrevivência, saúde e maturidade tendem a levar em conta o grau de agressão ao meio ambiente que seus produtos de consumo podem causar. Alguns aspectos considerados antes da compra são: a poluição que o produto pode gerar, o quanto o produto pode prejudicar as outras pessoas e o meio ambiente e o quanto este preserva o meio ambiente.

Para o fator de preocupação com a reciclagem, os resultados observados apresentaram semelhança com o fator anterior. $\mathrm{O}$ coeficiente de determinação $(\mathrm{R}=0,26$, $\mathrm{F}=3,42 ; p<0,003)$ indicou um total de $7 \%$ da variância explicada pelas funções psicossociais, ao passo que os critérios de orientação valorativa explicaram $4 \%$ da variância para este fator (correlação múltipla de $\mathrm{R}=$ $0,21, \mathrm{~F}=4,43 ; p<0,015)$.

Os valores observados para o $\beta$ padronizado na Tabela 3 dizem respeito aos coeficientes de correlações de cada variável com o fator de preocupação com reciclagem, considerando a correlação compartilhada entre os preditores. Para o critério de orientação dos valores centrais e a função psicossocial suprapessoal, os coeficientes de correlação foram, respectivamente, 0,22 e 0,24 .

Pode-se observar nesse fator que quanto mais as pessoas prezam valores como saúde e maturidade, por exemplo, mais tendem a se preocupar com as questões envolvidas na reciclagem dos produtos que consomem. Para aquisição dos seus produtos, essas pessoas levam em consideração aspectos como: embalagens reutilizáveis, produtos recicláveis e meios de reciclagem para o lixo doméstico.

O grupo das funções psicossociais explicou apenas $5 \%$ da variância para o fator de preocupação social (índice de correlação múltipla $\mathrm{R}=0,23, \mathrm{~F}=2,81$; $p$ $<0,011)$, sendo o mesmo percentual observado para os critérios de orientação $(\mathrm{R}=0,22, \mathrm{~F}=5,20 ; p<0,002)$. Esses resultados podem ser mais bem contemplados na tabela a seguir. 
Tabela 3 - Coeficientes observados para a regressão considerando os modelos com as funções psicossociais e os critérios de orientação para o fator de preocupação com reciclagem

\begin{tabular}{lccccc}
\hline \multicolumn{1}{c}{ Preditores } & $\beta$ & Erro padrão de $\beta$ & $\beta$ padronizado & $\mathrm{t}$ & $p$ \\
\hline Constante $^{1}$ & 1,01 & 0,69 & - & 1,46 & 0,145 \\
Constante $^{2}$ & 1,12 & 0,69 & - & 1,63 & 0,103 \\
\hline Pessoais & 0,00 & 0,08 & $-0,06$ & $-1,05$ & 0,292 \\
Experimentação & 0,00 & 0,06 & 0,02 & 0,29 & 0,773 \\
Realização & 0,00 & 0,06 & $-0,09$ & $-1,44$ & 0,149 \\
\hline Modais & 0,36 & 0,10 & 0,22 & 3,63 & 0,000 \\
Suprapessoais & 0,30 & 0,74 & 0,24 & 3,99 & 0,000 \\
Existência & 0,00 & 0,08 & 0,03 & 0,51 & 0,613 \\
\hline Sociais & 0,00 & 0,07 & $-0,05$ & $-0,78$ & 0,437 \\
Normativos & 0,00 & 0,06 & $-0,03$ & $-0,51$ & 0,612 \\
Interacionais & 0,00 & 0,08 & 0,01 & 0,22 & 0,824 \\
\hline \multicolumn{7}{r}{} & $\mathrm{R}$ & $\mathrm{R}^{2}$ & $\mathrm{R}^{2}$ Ajustado & Erro padrão da estimat. & \\
\hline Funções psicossociais & 0,26 & 0,07 & 0,05 & 0,85 & \\
Critérios de orientação & 0,21 & 0,04 & 0,03 & 0,86 & \\
\hline
\end{tabular}

1. Valor observado para esta componente considerando as funções psicossociais.

2. Valor observado para esta componente considerando os critérios de orientação valorativa.

Na Tabela 4, pode ser contemplado o impacto de cada variável nos dois modelos considerados. Mais uma vez as contribuições significativas estiveram concentradas nos valores centrais $(\beta=0,21)$ e na função psicossocial suprapessoal $(\beta=0,11)$.

Tais resultados indicam que, à medida que o sujeito prima por valores como justiça social, maturidade ou ainda sabedoria, existe uma tendência também a se preocupar com questões sociais na hora de comprar seus produtos. Seria o caso dos consumidores que, ao efetuarem suas compras, consideram se o produto é apresentado em propagandas que depreciam grupos minoritários, se as empresas têm preocupação social e se tratam de maneira digna seus funcionários.

Tabela 4 - Coeficientes observados para a regressão considerando os modelos com as funções psicossociais e os critérios de orientação para o fator de preocupação social

\begin{tabular}{lccccc}
\hline \multicolumn{1}{c}{ Preditores } & $\beta$ & Erro padrão de $\beta$ & $\beta$ padronizado & $\mathrm{t}$ & $p$ \\
\hline Constante $^{1}$ & 2,76 & 0,44 & - & 6,21 & 0,000 \\
Constante $^{2}$ & 2,75 & 0,44 & - & 6,28 & 0,000 \\
Pessoais & 0,00 & 0,05 & 0,08 & 1,39 & 0,167 \\
Experimentação & 0,00 & 0,04 & 0,10 & 1,05 & 0,100 \\
Realização & 0,00 & 0,04 & 0,01 & 0,13 & 0,896 \\
Modais & 0,21 & 0,06 & 0,20 & 3,27 & 0,001 \\
Suprapessoais & 0,11 & 0,05 & 0,14 & 2,33 & 0,020 \\
Existência & 0,00 & 0,05 & 0,12 & 1,86 & 0,064 \\
Sociais & 0,00 & 0,05 & 0,06 & 1,05 & 0,296 \\
Normativos & 0,00 & 0,04 & 0,06 & 0,97 & 0,331 \\
Interacionais & 0,00 & 0,05 & 0,01 & 0,18 & 0,854 \\
\hline \multicolumn{7}{r}{} & $\mathrm{R}$ & $\mathrm{R}^{2}$ & $\mathrm{R}^{2}$ ajustado & Erro padrão da estimat. & \\
\hline Funções psicossociais & 0,23 & 0,05 & 0,04 & 0,55 & \\
Critérios de orientação & 0,22 & 0,05 & 0,04 & 0,55 & \\
\hline
\end{tabular}

1. Valor observado para esta componente considerando as funções psicossociais

2. Valor observado para esta componente considerando os critérios de orientação valorativa 


\section{Discussão e conclusão}

Este estudo teve como interesse principal conhecer mais acerca do comportamento do consumidor paraibano e sua relação com os valores humanos. Não obstante, a literatura acerca desse tema tem insistentemente apontado para a necessidade de que os valores humanos sejam considerados agentes que, de alguma forma, influenciam a decisão do consumidor na hora de comprar, conforme discutido em Allen (2000), Gutman (1982) e Henry (1976).

Assim, foram realizadas análises exploratórias entre os escores obtidos por meio dos fatores da escala de intenção de comportamento do consumidor e os valores da tipologia de Gouveia (2003), sendo possível observar resultados coerentes entre tais construtos. Os valores centrais e, mais especificamente, a função psicossocial suprapessoal foram os únicos a apresentar contribuições para a explicação dos fatores da ECSRC.

A ocorrência desse fato está associada à especificidade da intenção do comportamento do consumidor mensurado pela escala, relacionado a aspectos sociais, que engloba, por sua vez, preocupação com o meio ambiente e também com o ser humano. Dessa forma, os valores mais voltados para características pessoais como emoção, estimulação, êxito e poder não puderam contribuir para explicação dos fatores contemplados pela ECSRC. O mesmo pode-se dizer dos valores sociais como obediência, ordem e apoio social, cujo foco de orientação está no desejo que o sujeito tem de se sentir considerado, de assegurar sua aceitação e sua integração no grupo. Esses valores não apresentaram contribuições significativas neste estudo, porque conceitualmente não apresentam relações com os aspectos do consumidor aqui abordados.

Sobre o construto com que os valores foram relacionados, cabe fazer uma ressalva sobre o tema abordado na ECSRC. Ainda que a escala utilizada conceba o construto como comportamento do consumidor, de fato, o que tem sido medido é a intenção relacionada a uma forma específica do consumidor se comportar. Nesse sentido, também é relevante ter parcimônia na interpretação dos resultados aqui apresentados, tendo em vista a necessidade de revisão do construto mensurado pela ECSRC, bem como o fato de se tratar de algo ainda mais específico.

Por fim, cabem ressaltar algumas limitações em relação às características sociodemográficas dos participantes deste estudo. As pesquisas realizadas sobre comportamento do consumidor tendem a levar em consideração, na seleção da amostra, o controle de variáveis como idade e renda, visto que se tratam de características muito associadas com o poder de escolha do consumidor (ver Roberts, 1996; Magnusson \& Hursti, 2002). A seleção da amostra universitária não permitiu esse tipo de controle nem tampouco que variáveis como essas pudessem ser comparadas. Dessa forma, sugere-se que estudos futuros procurem utilizar amostra da população geral e investigar se haverá diferença nos resultados.

\section{Referências}

Allen, M. W. (1997). The direct and indirect influences of buman values on consumer choices. Unpublished $\mathrm{PhD}$ thesis, Victoria University of Wellington, New Zealand.

Allen, M. W. (2000). The attribute-mediation and product meaning approaches to the influences of human values on consumer choices. Em F. Columbus (Org.). Advances in Psychology Research (v. 1, pp. 31-76). Huntington, NY: Nova Science.

Allen, M. W. \& Ng, S. H. (1999). The direct and indirect influences of human values on procuct ownership. Journal of Social Psychology, 45, 293-305.

Fishbein, M. (1967). A consideration of beliefs and their role in attitude measurement. Em M. Fishbein (Org.). Readings in attitude theory and measurement (pp. 257-266). New York: Wiley.

Gouveia, V. V. (2003). A natureza motivacional dos valores humanos: evidências acerca de uma nova tipologia. Estudos de Psicologia, 8, 431-443.

Gutman, J. (1982). A means-end chain model based on consumer categorisation processes. Journal of Marketing, 46, 60-72.

Henry, W. A. (1976). Cultural values do correlate with consumer behavior. Journal of Marketing Research, 13, 121-127.

Homer, P. \& Kahle, L. (1988). A structural equation test of the value-attitude-behavior hierarchy. Journal of Personality and Social Psychology, 54(2), 638-646.

Inglehart, R. (1991). Public support for environmental protection: objective problems and subjective values. Artigo apresentado no encontro anual da American Political Science Association, Chicago, IL.

Magnusson, M. K. \& Hursti, U. K. K. (2002). Comsumer attitudes towards genetically modified foods. Appeitte, 39, 9-24.

Maslow, A. H. (1954/1970). Motivation and personality. New York: Harper \& Row Publishers. 
Molpeceres, M. (1994). El sistema de valores: su configuración cultural y su socialización familiar en la adolescencia (Tese de Doutorado). Espanha: Universidade de Valência.

Queiroga, F. Gouveia, V. V., Coutinho, M. P. L. Vasconcelos, T. C. \& Jesus, G. R. (2005). Escala de comportamento socialmente responsável do consumidor: estudo preliminar de evidência de validade. Psicologia em Estudo, 10(1), 143-149.

Richins, M. L. (1994). Special possessions and the expression of material values. The Journal of Consumer Research, 21(3), 522-533.

Roberts, J. A. (1996). Will the real responsible consumer please step forward? Business Horizons, 39(5), 79 .

Rokeach, M. (1973). The nature of human values. New York: Free Press.

Rosemberg, M. J. (1956). Cognitive structure and attitudinal affect. Journal of Abnormal and Social Psychology, 53, 367-372.
Schwartz, S. H. (1992). Universals in the context and structure of values: Theoretical advances and empirical tests in 20 countries. Em M. Zanna (Org.). Advances in experimental social psychology (pp. 1-65). Orlando, FL: Academic Press.

Schwartz, S. H. (1994). Are there universal aspects in the structure and contents of human values? Journal of Social Issues, 50, 19-45.

Tabachnick, B. G. \& Fidell, L. S. (2001). Using multivariate statistics (4a ed.). Northridge, CA: HarperCollins College.

Sobre os autores:

Fabiaba Queiroga é psicóloga pela Universidade Federal da Paraíba, mestranda em Psicologia Social e do Trabalho na Universidade de Brasília, consultora em análise estatística de dados e metodologia de pesquisa. Atualmente é psicometrista da coordenadoria de avaliação no CESPE/UnB.

Valdiney V. Gouveia é professor da Universidade Federal da Paraíba, doutor em Psicologia Social pela Universidade Compultense de Madri, Espanha. É orientador de dissertações de mestrado e teses de doutorado do programa de pós-graduação da UFPB com o tema dos valores humanos.

Maria da Penha L. Coutinho é professora da Universidade Federal da Paraíba, doutora em Psicologia Clínica pela Universidade de São Paulo, USP. Fez pós-doutorado na Universidade Aberta de Lisboa, UAL, Portugal e atualmente orienta trabalhos com o tema de Representações Sociais.

Viviany Pessoa é psicóloga pela Universidade Federal da Paraíba, mestranda em Psicologia Ambiental pela Universidade Federal do Rio Grande do Norte. Desenvolveu vários estudos no núcleo de estudo sobre valores humanos e atualmente tem trabalhado com pesquisas relacionadas ao tema "Aspectos Psicológicos das Interações Pessoa-Ambiente".

Maja Meira é psicóloga pela Universidade Federal da Paraíba, mestre em Psicologia Social e do Trabalho pela Universidade de Brasília, professora e tutora de temas da Psicologia voltados para Administração, Educação e Relações Interpessoais. Consultora em análise estatística de dados e metodologia de pesquisa. Atualmente é analista de recursos humanos das Centrais Elétricas do Norte do Brasil - Eletronorte. 